University of Texas Rio Grande Valley

ScholarWorks @ UTRGV

Chemistry Faculty Publications and

Presentations

College of Sciences

10-15-2014

\title{
Thermodynamics, Kinetics, and Activation energy Studies of the sorption of chromium(III) and chromium(VI) to a Mn 304 nanomaterial
}

\author{
Yvette Cantu \\ The University of Texas Rio Grande Valley \\ Abril Remes \\ Alejandra Reyna \\ Denise Martinez \\ Jahaziel Villarreal
}

See next page for additional authors

Follow this and additional works at: https://scholarworks.utrgv.edu/chem_fac

Part of the Chemistry Commons

\section{Recommended Citation}

Cantu, Y., Remes, A., Reyna, A., Martinez, D., Villarreal, J., Ramos, H., Trevino, S., Tamez, C., Martinez, A., Eubanks, T., \& Parsons, J. G. (2014). Thermodynamics, Kinetics, and Activation energy Studies of the sorption of chromium(III) and chromium(VI) to a Mn304 nanomaterial. Chemical engineering journal (Lausanne, Switzerland : 1996), 254, 374-383. https://doi.org/10.1016/j.cej.2014.05.110

This Article is brought to you for free and open access by the College of Sciences at ScholarWorks @ UTRGV. It has been accepted for inclusion in Chemistry Faculty Publications and Presentations by an authorized administrator of ScholarWorks@ UTRGV. For more information, please contact justin.white@utrgv.edu,william.flores01@utrgv.edu. 


\section{Authors}

Yvette Cantu, Abril Remes, Alejandra Reyna, Denise Martinez, Jahaziel Villarreal, Hilda Ramos, Samantha Trevino, C Tamez, A Martinez, Thomas Eubanks, and Jason Parsons 


\title{
Thermodynamics, Kinetics, and Activation energy Studies of the sorption of chromium(III) and chromium(VI) to $\mathrm{ann}_{3} \mathrm{O}_{4}$ nanomaterial
}

\author{
Yvette Cantu, Abril Remes, Alejandra Reyna, Denise Martinez, Jahaziel Villarreal, Hilda \\ Ramos, Samantha Trevino, C. Tamez, A. Martinez, T. Eubanks, and J. G. Parsons ${ }^{*}$ \\ Department of Chemistry The University of Texas-Pan American Edinburg TX, 78539
}

\begin{abstract}
In this study, a manganese oxide, $\mathrm{Mn}_{3} \mathrm{O}_{4}$ was used to remove chromium(III) and chromium(VI) from aqueous solutions. The $\mathrm{Mn}_{3} \mathrm{O}_{4}$ nanomaterial was synthesized through a precipitation method, and was characterized using XRD, which confirmed the material had a crystal structure similar to hausmannite. In addition, using Scherrer's equation it was determined that the nanomaterial had an average grain size of $19.5 \pm 1.10 \mathrm{~nm}$. A study of the effects of $\mathrm{pH}$ on the binding of chromium(III) and chromium(VI) showed that the optimum binding $\mathrm{pH}$ was 4 and 3 respectively. Batch isotherm studies were performed to determine the binding capacity of chromium(III), which was determined to be $18.7 \mathrm{mg} / \mathrm{g}, 41.7 \mathrm{mg} / \mathrm{g}$, and $54.4 \mathrm{mg} / \mathrm{g}$ respectively for $4^{\circ} \mathrm{C}, 21^{\circ} \mathrm{C}$, and $45^{\circ} \mathrm{C}$. Chromium(VI) on the other hand had lower binding capacities of $2.5 \mathrm{mg} / \mathrm{g}$, $4.3 \mathrm{mg} / \mathrm{g}$, and $5.8 \mathrm{mg} / \mathrm{g}$ for $4^{\circ} \mathrm{C}, 21^{\circ} \mathrm{C}, 45^{\circ} \mathrm{C}$, respectively. Thermodynamic studies performed indicated the sorption process was for the most part controlled by physisorption. The $\Delta \mathrm{G}$ for the sorption of chromium(III) and Chromium(VI) ranged from -0.9 to $-13 \mathrm{~kJ} / \mathrm{mol}$, indicating a spontaneous reaction was occurring. The enthalpy indicated a endothermic reaction was occurring during the binding and show $\Delta \mathrm{H}$ values of 70.6 and $19.1 \mathrm{~kJ} . \mathrm{mol}$ for chromium(III) and Chromium(VI), respectively. In addition, $\Delta \mathrm{S}$ for the reaction had positive values of 267 and 73 $\mathrm{J} / \mathrm{mol}$ for chromium(III) and chromium(VI) which indicate a spontaneous reaction. In addition, the sorption process was found to follow pseudo second order kinetic and the activation energy studies indicated the binding process occurred through chemisorption.
\end{abstract}

\section{Keywords}

chromium(III); chromium(VI); adsorption; thermodynamics; $\mathrm{Mn}_{3} \mathrm{O}_{4}$ nanomaterials

\footnotetext{
(C) 2014 Elsevier B.V. All rights reserved.

*Corresponding Authror to whom all correspondence should be addressed. Ph: (956)665-7462, Fax: (956)665-5006, parsonsjg@utpa.edu.

This is a PDF file of an unedited manuscript that has been accepted for publication. as a service to our customers we are providing this early version of the manuscript. The manuscript will undergo copyediting, typesetting, and review of the resulting proof before it is published in its final citable form. Please note that during the production process errors may be discovered which could affect the content, and all legal disclaimers that apply to the journal pertain.
} 


\section{Introduction}

Increasing levels of heavy metal ions present in water and sewage systems pose increasing threats to both environmental and human health [1-23]. In 2008 it was reported by the U.S. EPA, that approximately 97,379 pounds of chromium was released annually into the environment through wastewater discharge $[2,4]$. Chromium exists commonly in two oxidation states, as either chromium(VI) or chromium(III) [2,4-7]. It is well known that chromium(VI) is carcinogenic, whereas chromium(III) is an essential nutrient [3-12]. Both chromium(VI) and chromium(III) are present in the environment at highly dangerous levels as industrial effluent discharges from steel works, oxidative dying, leather tanning industries, electroplating, volcanic eruptions, and cooling waters from coal fired power plants $[2-6,13,14]$. As a result, chromium is high on the list of priorities of the U.S. EPA's list of toxic pollutants [2,3]. AS a result of the contamination of the natural environment and the effects on human health it has become imperative to find an effective method to remove chromium from wastewaters.

Currently, a variety of methods have been developed to remove chromium from wastewaters, which include precipitation, ion exchange, reverse osmosis, electro-chemical precipitation, and adsorption [2, 4-6, 18, 20-22]. In addition, geopolymers, activated clays, chemical precipitation, and co-precipitation with metal hydroxides have also been investigated for the removal of chromium(VI) and chromium(III) from aqueous solution [8, 26, 27]. Other types of removal methods include: extraction, and ultrafiltration. However, most of these methods have major drawbacks, such as high costs. Overall, adsorption has proven to be one of the most effective methods for the removal of toxic metals from wastewaters due to its cost-effectiveness $[3,5,16,20]$. Many low-cost adsorbents have been studied such as, steel wool, sawdust, pine needles, shells, cactus leaves, magnesium pellets and iron oxide pellets among others. Structured metal oxides, such as manganese oxide have proved to be effective adsorbents in part due to their microporous structure, which allows for greater adsorption and high binding capacities [13, 16-19].

Interest has grown towards the used of nanomaterials as adsorbents for the removal and detoxification of toxic metals, due to the high surface area and reactive properties of nanomaterials. Nanomaterials have been shown to be an efficient and economical way to remove heavy metals from water [25]. Researchers have focused on nanomaterials due to their large surface area that allows nanomaterials to adsorb larger amounts of metal ions. Additionally, like other bulk materials some nanomaterials exhibit magnetic properties, which allow removal of both the nanomaterial and the contaminants from the water using magnetic separation $[3,4,25]$.

Previous studies have shown that both chromium(III) and chromium(VI) are effectively removed from solution through adsorption on to different materials. The sorption of chromium(VI) on to some nanomaterials has been show to first be reduced to chromium(III) which is followed by adsorption on to a metal oxide surface $[3,6,11,20]$. Removal of chromium ions has also been performed through the use of multiwall carbon nanotubes, instead of a metal oxide [21]. Although the method of adsorption and reduction with multiwall carbon nanotubes was successful, the process could be further simplified by 
finding a binding source that does not require the reduction of chromium(VI) to chromium(III). The removal of metal ions from aqueous solution can occur through three general processes which are as follows: dissolution of the material and co-precipitation of the metal ion and dissolved nanomaterial; ion-exchange with surface bound hydroxide and or protons; and through the process of physisorption of the ion to the surface of the nanomaterial.

In the present study the adsorption of chromium(III) and chromium(VI) on to $\mathrm{Mn}_{3} \mathrm{O}_{4}$ nanoparticles was investigated. The nanomaterial was synthesized using a slow titration of $\mathrm{MnCl}_{2}$ with dilute sodium hydroxide. Subsequently the solution was aged through heating the solution to convert the precipitated $\mathrm{Mn}(\mathrm{OH})_{2}$ to $\mathrm{Mn}_{3} \mathrm{O}_{4}$. The $\mathrm{Mn}_{3} \mathrm{O}_{4}$ nanomaterial was then characterized using XRD, which showed the nanoparticles had the crystal structure of hausmannite. The effects $\mathrm{pH}$ on the binding of chromium o the nanomaterials was investigated as well as the capacity of the nanomaterial for both chromium(III) and chromium(VI) at different temperatures. The thermodynamics of the binding process were investigated, which included determining the $\Delta \mathrm{G}, \Delta \mathrm{H}$, and $\Delta \mathrm{S}$. The thermodynamic parameters will provide insight to the binding mechanism of chromium ions to the surface of the nanomaterial. The kinetics of the sorption process were studied at temperatures of 4,25 , and $45^{\circ} \mathrm{C}$. From the kinetics data the activation energy for the process was determined using Arrhenius plots providing insight into the binding process.

\section{Methods}

\subsection{Synthesis of nanoadsorbents}

A $1.0 \mathrm{~L} 30.0 \mathrm{mM}$ solution of $\mathrm{MnCl}_{2}$ was titrated with $90 \mathrm{~mL}$ of $1 \mathrm{M} \mathrm{NaOH}$ for over 2 hours. The solution was heated to $90^{\circ} \mathrm{C}$ for $10-20$ minutes to induce formation of the $\mathrm{Mn}_{3} \mathrm{O}_{4}$. Subsequent to heating the solution was cooled to room temperature and centrifuged at 3000 RPM for 10 minutes. The supernatants were discarded and the test tubes containing the remaining nanomaterial were washed twice using $18 \mathrm{M} \Omega$ DI water. The washed nanomaterials were then oven died at $65^{\circ} \mathrm{C}$ for 12 hours to remove any residual water in the nanomaterials.

\subsection{Nanomaterial Characterization}

The X-ray diffraction patterns were collected using a Rigaku Miniflex X-Ray powder diffractometer, using a $\mathrm{Cu}$ source $\left(\mathrm{Cu} \mathrm{K} \mathrm{C}_{\mathrm{a}}\right)$. The scans were acquired from 15-60.4 in $2 \theta$ with a counting time of 2 seconds and a step of $0 . \theta 2^{\circ}$ in 20 . The collected diffraction pattern was then fittied using the Le Bail fitting procedure, in the Fullprof software package for confirmation of the structure of the nanomaterial. In addition, the average grain size of the nanomaterial was determined using the Scherrer's equation. The size analysis was performed using the full width half maximum of a minimum of three independent diffraction peaks for the $\mathrm{Mn}_{3} \mathrm{O}_{4}$ nanomaterial. The SEM analysis was performed on a Zeiss EVOLS10. The samples were fixed to an aluminum post using carbon tape, and sputter coated using an Au-Pd sputtering target. The Instrument was operated at a voltage of $23.34 \mathrm{kV}$ and a working distance of $4.5 \mathrm{~mm}$. 


\section{$2.3 \mathrm{pH}$ Profile}

Chromium(III) and chromium(VI) were tested for adsorption onto $\mathrm{Mn}_{3} \mathrm{O}_{4}$ nanomaterial over a pH range of 2-6. $300 \mathrm{ppb}$ solutions of both chromium(III) and chromium(VI) were prepared and diluted, the $\mathrm{pH}$ adjustment was achieved using either dilute sodium hydroxide and/or dilute nitric acid to the desired $\mathrm{pH}$. A $4.0 \mathrm{~mL}$ of the aliquot of the $\mathrm{pH}$ adjusted solution was transferred to a $5.0 \mathrm{~mL}$ test tube containing $10 \mathrm{mg}$ of the nanomaterial in triplicate. In addition control samples were prepared in a similar manner without the presence of the nanomaterial. The test tubes were then capped and equilibrated on a test tube rocker for one hour. Subsequent to equilibrium the samples and controls were centrifuged at 3000 RPM for 10 minutes and the supernatants was saved further analysis. Each sample was repeated in triplicate for $\mathrm{QA} / \mathrm{QC}$ and statistical purposes. The samples and controls then analyzed using a Perkin Elmer AAnalyst 800 in Graphite Furnace Atomic Absorption Spectroscopy (GFAAS) mode. The amount of chromium bound to the nanoadsorbent was then determined by the difference method. In addition all calibration curves were generated for the study had correlation coefficients $\left(\mathrm{R}^{2}\right)$ of 0.99 or better.

\subsection{Capacity Studies}

The optimum binding $\mathrm{pH}$ for both chromium(III) and chromium(VI) was determined to be $\mathrm{pH} 4$ from the $\mathrm{pH}$ profile study. The capacities were determined using isotherm studies with solutions containing $0.3,3,30,300$, and $1000 \mathrm{ppm}$ of either chromium(III) or chromium(VI). The $\mathrm{pH}$ adjusted chromium solutions were added to test tubes containing 10 $\mathrm{mg}$ of manganese oxide $\left(\mathrm{Mn}_{3} \mathrm{O}_{4}\right)$. Each concentration was repeated in triplicate and the control samples prepared in a similar manner as the samples. The test tubes were capped and put on a test tube rocker for one hour to insure equilibration, following the equilibration the sample and control test tubes were centrifuged at $3000 \mathrm{RPM}$ for $10 \mathrm{~min}$. The supernatant were saved and analyzed using a Perkin Elmer Optima 8300 DV ICP-OES. In addition, all calibration curves were generated for the study had correlation coefficients $\left(R^{2}\right)$ of 0.99 or better.

\subsection{Thermodynamic studies}

Several thermodynamic studies were conducted for chromium(III) and chromium(VI) at different temperatures. The solutions were prepared at various concentrations the same as the capacity studies ranging from $0.3 \mathrm{ppm}$ to $1000 \mathrm{ppm}$ for chromium(III) or chromium(VI). The $\mathrm{pH}$ of the solution was adjusted to the optimum binding $\mathrm{pH}$ of $4.4 .0 \mathrm{~mL}$ aliquots of the solutions were added to test tubes, containing $10 \mathrm{mg}$ of $\mathrm{Mn}_{3} \mathrm{O}_{4}$, and equilibrated for one hour on a test tube rocker at temperatures of $4{ }^{\circ} \mathrm{C}, 21^{\circ} \mathrm{C}$ (room temperature), and $45^{\circ} \mathrm{C}$. Subsequent to equilibration samples and controls were then centrifuged for at $3000 \mathrm{rpm}$ for $10 \mathrm{~min}$. The supernatants were saved for analysis using ICP-OES (Inductively Coupled Plasma-Optical Electron Spectroscopy). Calibration curves were generated with correlation coefficients $\left(\mathrm{R}^{2}\right)$ of 0.99 or better. The study was performed in triplicate for QA/QC and statistical purposes. 


\subsection{Kinetic Studies}

Solutions consisting of $3.0 \mathrm{mM}$ of either chromium(III) or chromium(VI) were prepared from chromium(III) nitrate or potassium dichromate. A $4 \mathrm{ml}$ aliquot was $\mathrm{pH}$ adjusted $\mathrm{pH} 4.0$ using either dilute sodium hydroxide or dilute nitric acid at temperatures of $4{ }^{\circ} \mathrm{C}, 25^{\circ} \mathrm{C}$, or $45^{\circ} \mathrm{C}$. The $\mathrm{pH}$ adjusted chromium solution was then added to a polyethylene test tube containing $10 \mathrm{mg}$ of the $\mathrm{Mn} 3 \mathrm{O} 4$ nanomaterial. The reactions were then equilibrated for the following times 10, 15, 20, 30, 60, 90, 120, and 240 minutes. Once the solutions were finished equilibrating for the specified time the samples were centrifuged for 5 minutes at $3,000 \mathrm{rpm}$ and the supernatants were decanted and saved for analysis using ICP-OES. In addition, control samples containing only chromium ions were also processed the same as the reaction samples. Furthermore, the samples and control samples were prepared and analyzed in triplicate for statistical purposes.

\subsection{Activation Energy Studies}

Once the kinetic data was collected and the rate constant was determined for the reaction at the three different temperatures an Arrhenius plot was developed. The Arrhenius plot was developed by plotting the Ln k against 1/T (in Kelvin). The linearized form of the Arrhenius equation is given below in equation 1 :

$$
\operatorname{Lnk}=\frac{E_{a}}{R}\left(\frac{1}{T}\right)+\operatorname{Ln} A \quad 1
$$

Where $\mathrm{k}$ is the rate constant for the reaction at a given temperature, Ea is the activation energy for the process, $\mathrm{R}$ is the gas constant (8.314), $\mathrm{T}$ is the temperature given in Kelvin, and $\mathrm{A}$ is the frequency factor for a given reaction.

\subsection{ICP-OES Analysis}

ICP-OES analysis was performed using a Perkin Elmer Optima 8300 DV ICP-OES.

Calibrations were conducted by using three standards, with the addition of a blank solution. The calibration range was between $1.00 \mathrm{ppm}$ to $100 \mathrm{ppm}$. Samples over the range of the standards were diluted to be within range. The operating conditions for the ICP-OES are shown below in Table 1. Furthermore, all standards, controls, and samples were read in triplicate for statistical purposes.

\subsection{GFAAS analysis}

GFAAS analysis was performed using a Perkin Elmer AAnalyst 800 in Graphite Furnace Atomic Absorption mode. The operational parameters of the GFAAS are shown below in Table 2. The wavelength for the analysis was $357.9 \mathrm{~nm}$ with a hollow cathode lamp with a slit of $0.7 \mathrm{~nm}$ and a lamp current of $8 \mathrm{~mA}$. A sample injection of $20 \mu \mathrm{L}$ and no matrix modifier was used for the analysis of chromium. Furthermore, all standards, controls, and samples were read in triplicate for statistical purposes. 


\subsection{Results and Discussion}

\subsection{X-Ray Diffraction Analysis}

Figure 1 shows the X-Ray diffraction patterns collected for the synthesized $\mathrm{Mn}_{3} \mathrm{O}_{4}$ nanomaterial after washing and drying. The Bragg peaks for the synthesized $\mathrm{Mn}_{3} \mathrm{O}_{4}$ nanomaterial are indicated on the bottom of the plot. It was determined from the diffraction analysis that the nanomaterial was $\mathrm{Mn}_{3} \mathrm{O}_{4}$ in a tetragonal lattice with space group $\mathrm{I}_{1} / \mathrm{AMD}$. The refined lattice parameters determined from the Le Bail fitting were as follows a $=5.77$ $\mathrm{nm}, \mathrm{C}=9.45, \alpha=\beta=\gamma=90.0^{\circ}$, which match the parameters determined for hausmannite from the literature [28]. The Bragg peaks identified as present in the nanomaterial correspond to $200\left(18.0^{\circ}\right), 112\left(28.9^{\circ}\right), 200\left(31.0^{\circ}\right), 103\left(32.3^{\circ}\right), 211\left(36.0^{\circ}\right), 202\left(36.5^{\circ}\right)$, $004\left(38.1^{\circ}\right), 220\left(44.4^{\circ}\right), 301\left(48.2^{\circ}\right), 204\left(49.9^{\circ}\right), 105\left(50.9^{\circ}\right), 321\left(58.5^{\circ}\right), 224\left(59.9^{\circ}\right)$ and the from left to right in the plot (the peak positions are given in $2 \theta^{\circ}$ in brackets). The average grain size of the nanomaterial was determined using the Scherrer's equation and analysis, using three independent diffraction peaks which gave an average grain size of the materials was determined to be $19.5 \pm 1.10 \mathrm{~nm}$. The small errors on the calculated size of the nanomaterials indicate low anisotropy and that the nanomaterials spherical in shape. Figure $2 \mathrm{~A}$ and B show a SEM Image of the synthesized nanomaterial. The SEM image indicates that the synthesized nanomaterials are spherical in shape. Furthermore, the SEM images shows that the nanomaterials are clustered together forming larger structures again with spherical shapes and diameters ranging from 30 to approximately $60 \mathrm{~nm}$. The spherical natures of the nanomaterials seen in the SEM image corroborate the shape inferred from the XRD data.

\section{$3.2 \mathrm{pH}$ Studies}

Figure $3 \mathrm{~A}$ and 3B show the $\mathrm{pH}$ binding for chromium(III) and chromium(VI) binding to manganese oxide $\left(\mathrm{Mn}_{3} \mathrm{O}_{4}\right)$ nanomaterial from $\mathrm{pH} 2$ to $\mathrm{pH}$ 6, respectively. In Figure $3 \mathrm{~A}$, the abnormally high binding of chromium(III) at low $\mathrm{pH}, \mathrm{pH} 2$ and $\mathrm{pH} 3$, is due to a redox reaction, occurring between the $\mathrm{Mn}$ and the Chromium(III) ions. The redox reaction has been noted in the literature and has been shown to occur at $\mathrm{pH} 2$ and $\mathrm{pH} 3$ (29). The redox reaction between the $\mathrm{Mn}$ in the nanomaterial and the chromium(III) results in the oxidation of the chromium(III) to chromium(VI). However, at $\mathrm{pH} 4$ and above the binding of the Chromium(III) to the nanomaterial has decreased and stabilized indicating that the oxidation of the chromium(III) has stopped and the removal of the chromium is due to adsorption. Due to the presence of the redox reaction between the $\mathrm{Mn}$ in the nanomaterial and chromium(III) ions and the observation of the stabilized binding observed at $\mathrm{pH} 4$ and above, $\mathrm{pH} 4$ was selected as the optimum binding $\mathrm{pH}$. The binding of the chromium(VI) ion is shown in Figure $2 \mathrm{~B}$, as can be seen the binding decreases with increasing $\mathrm{pH}$ from $90 \%$ binding at $\mathrm{pH} 2$ to approximately $20 \%$ binding at $\mathrm{pH} 4$. The $\mathrm{pH}$ profiles are in agreement with the literature for chromium binding to other metal oxide nanomaterials $[9,10,13,26,30]$. For example, nano- $\mathrm{Fe}_{3} \mathrm{O}_{4}$ magnetic polymers have shown a similar $\mathrm{pH}$ binding trend of decreasing binding $\mathrm{pH}$ increases, with $\mathrm{pH} 2$ having a maximum adsorption of 99\% [2]. Similar binding trends have been observed with chromium binding to $\mathrm{Fe}_{3} \mathrm{O}_{4}, \mathrm{MnFe}_{2} \mathrm{O}_{4}$, $\mathrm{TiO}_{2}, \mathrm{Al}_{2} \mathrm{O}_{3}, \mathrm{Fe}_{2} \mathrm{O}_{3}$, and among other metal oxide nanomaterials [4, 31-41]. The relationship in the binding is generally due to the surface charge of the nanomaterial, at low 
$\mathrm{pH}$ the surface of a nanomaterial is protonated giving the nanomaterial a slightly positive charge whereas at high $\mathrm{pH}$ the nanomaterial becomes neutral and then negatively charged. At high $\mathrm{pH}$ values above the zero point charge of the nanomaterial the surface of the nanomaterial is negatively charged and thus repulses the chromium(VI) anions and the binding becomes greatly diminished $[4,13]$. Conversely, at a low $\mathrm{pH}$ chromiumn(VI) can be efficiently adsorbed from solution [18]. In general chromium(III) follows an opposite trend in the binding when compared to chromium(VI). However, at low $\mathrm{pH}$ in the presence of $\mathrm{Mn}$ nanomaterials redox reactions occur, as previously mentioned which disrupts the generally observed binding trend for chromium(III).

\subsection{Capacity Studies}

The adsorption capacities of chromium(III) and chromium(VI) binding to $\mathrm{Mn}_{3} \mathrm{O}_{4}$ were performed at three different temperatures, which were as follows: $4^{\circ} \mathrm{C}, 26^{\circ} \mathrm{C}$ and $45^{\circ} \mathrm{C}$. The data presented in Table 3 shows chromium(III) had a much higher binding capacity to the $\mathrm{Mn}_{3} \mathrm{O}_{4}$ nanomaterial than the chromium(VI), approximately 9 times the binding capacity. However, the binding capacity was shown to increase with increasing temperature with a maximum capacity occurring at a temperature of $45^{\circ} \mathrm{C}$ for both chromium(III) and chromium(VI). It was evident at the $4^{\circ} \mathrm{C}$ study where the binding capacity for both chromium(III) and chromium(VI) were the lowest. The data from the capacity study was determined using an isotherm study, which was found to follow the Langmuir isotherm model. As shown in Table 2 the correlation for the fittings of the data to the Langmuir isotherm are all $0.99\left(\mathrm{R}^{2}\right)$ or better. The data fitting to a Langmuir isotherm indicate a monolayer adsorption is occurring. The adsorption of a monolayer of the ions on the materials at $\mathrm{pH} 4$ indicates that at this $\mathrm{pH}$ the redox reaction occurring at lower $\mathrm{pH}$ 's has stopped.

The data in the current study are for the most part in the same concentrations ranges as those other stuides, using different nanoadsorbents of similar structure, where capacities for chromium(III) and chromium(VI) were 7 to $10 \mathrm{mg} / \mathrm{g}$ for chromium(III) and around $3 \mathrm{mg} / \mathrm{g}$ for chromium(VI) [4]. Other studies also confirm the higher binding capacities of chromium(III) when compared to chromium(VI) $[6,17]$. Zeolites have been shown to have capacities as high as $26 \mathrm{mg} / \mathrm{g}$ whereas Fly ash has shown to have capacities of $2.3 \mathrm{mg} / \mathrm{g}$ for chromium(III). Chromium(VI) has been shown to have a capacity of $5 \mathrm{mg} / \mathrm{g}$ on $\mathrm{TiO}_{2}, 7.44$ $\mathrm{mg} / \mathrm{g}$ on activated alumina, $12.9 \mathrm{mg} / \mathrm{g}$ on activated carbon, and up to $51.5 \mathrm{mg} / \mathrm{g}$ on hydrous zirconium oxide $[38,42,43]$. Other examples of capacities of chromium binding to different materials are presented in Table 4 for comparative purposes. However, data obtained from capacity studies do have a large variation, which presents limitations for comparisons. These limitations generally present due to differences in the reaction conditions. In addition, parameters such as size, porosity, and stability of the nanomaterial as well as all preparation methods can contribute to the variability of binding capacity [4].

\subsection{Thermodynamic Studies}

The thermodynamic data obtained determined from the present study is presented in Table 4-Table 6 for the Gibbs free energy, the enthalpy, and the entropy of the binding system. The change in the Gibbs free energy $(\Delta \mathrm{G})$ was calculated for both the chromium(III) and 
chromium(VI) ions based on the relationship between the distribution coefficient or equilibrium constant between the chromium ions and the nanomaterial. The relationship between shown in equation 2 :

$$
\Delta G=-R T \operatorname{Ln} K_{d} \quad 2
$$

$\Delta \mathrm{G}$ is the calculated change in the Gibbs free energy, $\mathrm{R}$ is the gas constant $(8.314 \mathrm{~J} /$ $\mathrm{Mol}^{-1} \mathrm{~K}^{-1}$ ), $\mathrm{T}$ is the absolute temperature in Kelvin, and $\mathrm{K}_{\mathrm{d}}$ is the distribution coefficient. The calculated thermodynamic values for the adsorption of chromium(III) and chromium(VI) onto $\mathrm{Mn}_{3} \mathrm{O}_{4}$ are presented in Table 5. The general trend in the changes in Gibbs free energy for both the chromium(III) and chromium(VI) ions gets more negative as temperature increases indicating a more spontaneous reaction as temperature increases. The thermodynamic parameters for the sorption of both chromium(III) and chromium(VI) has been studied in the literature for many different inorganic materials including metal oxides $[4,34,38,44]$. For example Luther et al nanoma the thermodynamics of chromium (III) and chromium(VI) to $\mathrm{Fe}_{3} \mathrm{O}_{4}$ and $\mathrm{MnFe}_{2} \mathrm{O}_{4}$ terials [4]. For the binding to chromium(VI) to these nanomaterials the $\Delta \mathrm{G}$ for the sorption process range between -7.5 to -7.02 and was dependent on the temperature. Whereas, the binding of chromium(III) to the same materials was found to be between -17.16 to $-11.40 \mathrm{KJ} / \mathrm{mol}$. Which are were found to be slightly higher than the values found in the present study, which were $-2.7 \mathrm{~kJ} / \mathrm{mol}(277 \mathrm{~K}),-10.7$ $\mathrm{kJ} / \mathrm{mol}(298 \mathrm{~K})$ and $-13.7 \mathrm{~kJ} / \mathrm{mol}(318 \mathrm{~K})$ for chromium(III) and $-0.9 \mathrm{~kJ} / \mathrm{mol}(277 \mathrm{~K}),-2.8$ $\mathrm{kJ} / \mathrm{mol}(298 \mathrm{~K})$ and $-3.9 \mathrm{~kJ} / \mathrm{mol}(318 \mathrm{~K})$ for chromium(VI). A similar trend was observed for the change in the $\Delta \mathrm{G}$ in the present study as was observed by Luther et al, which the change becomes more negative with increasing temperature indicating a spontaneous process that is endothermic. In similar types of materials such as synthetic hematite the $\Delta \mathrm{G}$ was shown to be $1.6 \mathrm{~kJ} / \mathrm{mol}$ at $300 \mathrm{~K}$, whereas with mixed aluminum-magnesium metal hydroxides the $\Delta \mathrm{G}$ has been shown to range from -6.26 to $-8.96 \mathrm{~kJ} / \mathrm{mol}[8,45]$. In modified clays the $-40 \mathrm{~kJ} / \mathrm{mol}$ showed a very spontaneous reaction [46]. The sorption of chromium(III) to bentonite has been shown to have a $\Delta \mathrm{G}$ of $-3.91 \mathrm{~kJ} / \mathrm{mol}$ and a $\Delta \mathrm{G}$ for chromium(VI) of $-0.441 \mathrm{~kJ} / \mathrm{mol}$ [44]. It has been shown in the literature that a $\Delta \mathrm{G}$ value below $18 \mathrm{~kJ} / \mathrm{mol}$ (absolute value) indicates the reaction is an adsorption process dominated by physisorption [47]. However with a $\Delta \mathrm{G}$ value approximately from -34 to $-40 \mathrm{~kJ} / \mathrm{mol}$ indicates ion exchange is the predominate mechanism for the sorption equilibrium [47]. This would indicate that the present study the binding of both chromium(III) and chromium(VI) to the nanomaterials is predominately though physisorption and not ion exchange. Furthermore, the increase in magnitude for the calculated values indicates that adsorption becomes more favorable as temperatures increase, indicating the adsorption is through an endothermic process.

The determined $\Delta \mathrm{H}$ and $\Delta \mathrm{S}$ values for the present study are shown in Table 6 for the binding of both chromium(III) and chromium(VI) ions to the $\mathrm{Mn}_{3} \mathrm{O}_{4}$ nanomaterial. The relationship between $\Delta \mathrm{G}, \Delta \mathrm{H}$, and $\Delta \mathrm{S}$ and the relationship between $\Delta \mathrm{G}$ and the $\mathrm{Ln} \mathrm{K}_{\mathrm{d}}$ show in equation 2 and equation 3 , respectively.

$$
\Delta \mathrm{G}=\Delta \mathrm{H}-\mathrm{T} \Delta \mathrm{S} \quad 3
$$


The following relationship can be determined substituting $\operatorname{Ln} \mathrm{K}_{\mathrm{d}}$ into equation 2 to develop equation 4.

$$
\operatorname{Ln} K_{d}=\frac{\Delta S}{R}-\frac{\Delta H}{R T} \quad 4
$$

By plotting the $\mathrm{LnK}_{\mathrm{d}}$ against $1 / \mathrm{T}$ (in $\mathrm{K}$ ) the $\Delta \mathrm{H}$ of the reaction can be determined from the slope of the line and from the intercept of the plot $\Delta \mathrm{S}$ can be determined. Figure 4 shows the plots of Ln Kd determined at the three different temperatures $277 \mathrm{~K}, 298 \mathrm{~K}$ and $318 \mathrm{~K}$ for both chromium(III) and chromium(VI) binding to the $\mathrm{Mn}_{3} \mathrm{O}_{4}$ nanomaterial. Table 6 shows the determined $\Delta \mathrm{H}$ values for the binding of the chromium(III) and chromium(VI) to the nanomaterial. The positive values determined for the binding of both chromium(III) and chromium(VI) to the nanomaterial indicates that the reaction is endothermic in nature. In addition, the binding of chromium(III) ion to manganese oxide nanomaterial has a much higher $\Delta \mathrm{H}$ than the chromium(VI) as can be seen in Table 6 indicating the chromium(III) ion binding is more endothermic than the binding of chromium (VI) ions. Furthermore, the apparent $\Delta \mathrm{H}$ value of the binding of chromium(VI) was below $40 \mathrm{~kJ} / \mathrm{mol}$ indicating that the binding occurred through physisorption, as was suggested by the $\Delta \mathrm{G}$ results which has been indicated in the literature [43]. However, the apparent $\Delta \mathrm{H}$ for the binding of chromium(III) ions to the nanomaterials was determined to above $40 \mathrm{~kJ} / \mathrm{mol}$, appromixately $70 \mathrm{~kJ} / \mathrm{mol}$, indicating that the reaction is not driven solely though physisorption. For the binding of chromium(III) it may physisorption complimented by an ion exchange or chemisorption to the surface of the $\mathrm{Mn}_{3} \mathrm{O}_{4}$ nanomaterial.

The calculated entropy $\Delta \mathrm{S}$ values for this study are shown in Table 6 for the binding of chromium(III) and chromium(VI) ions to $\mathrm{Mn}_{3} \mathrm{O}_{4}$ nanomaterial. The $\Delta \mathrm{S}$ for the binding of both chromium(III) and chromium(VI) are both positive values and thus the binding is a thermodynamically favorable reaction. The very high entropy for the chromium(III) binding reaction would indicate that some material is being released from the $\mathrm{Mn}_{3} \mathrm{O}_{4}$ material which supports a binding mechanism that would involve ion exchange in addition to physisorption. Alternatively, reductive dissolution of the $\mathrm{Mn}_{3} \mathrm{O}_{4}$ could be occurring in the reaction mixture which would lead to an increase in the entropy of the system. Reductive and oxidative dissoloution of nanomaterials has been suggest in the literature for the binding of different ions to nanomaterials $[4,19]$. The lower entropy observed for chromium(VI) could indicate a reduction mechanism through which chromium(VI) is reduced to chromium(III) as a result of donation of electrons from the surface of the nanomaterial [4]. In a similar study, chromium(III) and chromium(VI) was tested with $\mathrm{MnFe}_{2} \mathrm{O}_{4}$ and $\mathrm{Fe}_{3} \mathrm{O}_{4}$ nanomaterial under light and dark conditions, the $\Delta \mathrm{S}$ values obtained for chromium(III) were $69.26 \mathrm{~J} / \mathrm{mol}$ and $22.95 \mathrm{~J} / \mathrm{mol}$ for $\mathrm{MnFe}_{2} \mathrm{O}_{4}$ and $\mathrm{Fe}_{3} \mathrm{O}_{4}$.

\subsection{Kinetic Studies}

The Results of the Kinetics study were found to best follow the second-order or pseudo order adsorption kinetics model. The linear second order and pseudo second order equation for the adsorption of a metal ion to the surface of an adsorbent is shown below in equation 5 [48]: 


$$
\frac{t}{q_{t}}=\frac{1}{k q_{e}^{2}}+\frac{t}{q_{e}} \quad 5
$$

Where $\mathrm{q}_{\mathrm{t}}$ is the adsorption at any given time during the reaction, $\mathrm{t}$ is the time for the adsorption given in minutes, $\mathrm{q}_{\mathrm{e}}$ is the equilibrium adsorption of the metal ion to the surface, and $\mathrm{K}$ is the rate constant for the given reaction. As can be seen in Figure 5 both the chromium(III) and chromium(VI) adsorption follow the second order or pseudo second order reaction kinetics. The correlation coefficients for both the chromium(II) and chromium(VI) are 0.99 or better. The pseudo second order kinetic model nicely simulated the data obtained in the study. From the kinetics plots the rate constants were determined as shown in Table 6. As can be seen in Table 6 the rate constant $(\mathrm{k})$ for the reaction increased with increasing temperature. The observed increase in rate constant with increasing temperature indicates that the reaction is endothermic reaction for the binding of both chromium(III) and chromium(VI) to the $\mathrm{Mn}_{3} \mathrm{O}_{4}$ nanomaterial. The endothermic reaction was also indicated in the thermodynamic studies as mentioned earlier. The observed pseudo second order reaction kinetics has been shown to fit the data for chromium binding to magnetite nanomaterials, diatomite-magnetite supported nanomaterials, and chromium(VI) binding to maghemite nanoparticles $[49,50]$. Furthermore the pseudo-second order kinetic model has also been used to model the adsorption kinetics of methylene blue on to palm kernel fiber [50]. The as well as the binding of cadmium(II) ions onto zero valent iron, $\mathrm{As}(\mathrm{V})$ adsorption onto clinoptilolite with iron or aluminum oxide, with comparable rates observed in this study for chromium(VI) and chromium(III) [51, 52]. It has been suggested that there is a activation process occurring during the adsorption process. As can be seen in the data for the sorption of chromium(III) and chromium(VI) the rate constant for the sorption of chromium(III) are much higher than the rate constants associated with the chromium(VI) ions. The higher observed rate constants for the chromium(III) may be an effect of the charge of the chromium(III) in solution which should be positive. Whereas the $\mathrm{Cr}(\mathrm{VI})$ ions in solution have a net negative charge which may cause repulsion between the chromium(VI) and the hydration sphere around the nanomaterial and thus slow the kinetics of adsorption. There are a number of important factors for adsorption of an ion to any material. However, there must be an attractive force between the material and the ions before the process starts. The Kinetics for the chromium(VI) may be slowed by breaking apart of the hydration sphere and the diffusion to the surface of the material as compared to the chromium(III).

\subsection{Activation Energy Studies}

From the kinetics data obtained at different temperatures the activation energy for the binding of both chromium(III) and chromium(VI) was determined as shown in Table 7, and the Arrhenius plot is shown in Figure 6. As can be seen in Table 7 the activation energy for the binding of both chromium(III) and chromium(VI) to the $\mathrm{Mn}_{3} \mathrm{O}_{4}$ nanomaterials are very similar with only a difference of approximately $8 \mathrm{~kJ}$. The slight difference in the activation energy for the binding process may be indicating a slight different affinity of the metal ions to the $\mathrm{Mn}_{3} \mathrm{O}_{4}$ nanomaterial. However, the similarity in the activation energy for the binding of both ions does indicate that the ions are going through a similar process in binding. The 
magnitude if the activation energy can be used to help elucidate the mechanism occurring for the binding, whether the binding is through physisorption or through chemisorption. Physisorption, a physical attraction generally has activation energies below $40 \mathrm{KJ} / \mathrm{mol}$ [52]. Whereas, chemisorption is a chemical process requires more energy and generally has activation energies above $40 \mathrm{~kJ} / \mathrm{mol}$ [52]. The data from the activation energy studies indicates that the binding process for both the chromium(III) and chromium(VI) ions to the $\mathrm{Mn}_{3} \mathrm{O}_{4}$ nanomaterials occurs through chemisorption as both ions have activation energies above $40 \mathrm{~kJ} / \mathrm{mol}$. The action energies are similar in magnitude to those observed for cadmium(III) binding to zero valent iron nanoparticles which was observed to be $54 \mathrm{~kJ} / \mathrm{mol}$ [52].

\section{Conclusions}

A Manganese oxide nanomaterial, $\mathrm{Mn}_{3} \mathrm{O}_{4}$, was synthesized, characterized using XRD, and tested for the removal of both chromium(III) and chromium(VI). The optimum binding $\mathrm{pH}$ for each material was determined using batch $\mathrm{pH}$ studied and was found to be $\mathrm{pH} 4$ for chromium(III) and $\mathrm{pH} 3$ for chromium(VI). The binding capacities of the nanomaterials were determined at temperatures of $4^{\circ} \mathrm{C}(277 \mathrm{~K}), 25^{\circ} \mathrm{C}(298 \mathrm{~K})$, and at $45^{\circ} \mathrm{C}(318 \mathrm{~K})$, for chromium(III) these were $18.7 \pm 2.1 \mathrm{mg} / \mathrm{g}, 41.7 \pm 1.7 \mathrm{mg} / \mathrm{g}$, and $54.4 \pm 4.3 \mathrm{mg} / \mathrm{g}$, respectively. The chromium(VI) binding capacities for the same temperature series were significantly lower $2.5 \pm 0.3,4.3 \pm 0.7$ and $5.8 \pm 0.3 \mathrm{mg} / \mathrm{g}$, respectively. The thermodynamic parameters from the study indicate that the sorption of the chromium is spontaneous as determined from the negative $\Delta \mathrm{G}$ values obtained from both the chromium(III) and chromium(VI). Also, the reaction of chromium(III) with the $\mathrm{Mn}_{3} \mathrm{O}_{4}$ nanomaterial occurs through a combination of physisorption and possibly ion-exchange, whereas the chromium(VI) sorption appears to be mainly physisorption. Furthermore, the $\Delta \mathrm{S}$ showed an increase, which could be indicating that some ion-exchange is occurring during sorption, or the randomness at the surface and water interface is increasing during the sorption process. In addition, the sorption process was also found to follow pseudo second order kinetics, and from the activation energy studies the binding occurs through a chemisorption process.

\section{Acknowledgments}

Authors would like to thank the NIH UTPA RISE program (Grant Number 1R25GM100866-01), NSF, URM program (grant number DBI 9034013), HHMI (grant 52007568). The Authors acknowledge financial support from the Welch Foundation for supporting the Department of Chemistry (Grant number GB-0017), and UTPA for sponsoring this research project.

\section{References}

1. Gardea-Torresdey JL, Tiemann KJ, Parsons JG, Gamez G, Yacaman J. Characterization of trace level Au(III) binding to alfalfa biomass (Medicago sativa) by GFAAS. Adv. Environ. Res. 2002; 6(3):313-323.

2. Zhao YG, Shen HY, Pan SD, Hu MQ, Xia QH. Preparation and characterization of aminofunctionalized nano- $\mathrm{Fe}_{3} \mathrm{O}_{4}$ magnetic polymer adsorbents for removal of chromium(VI) ions. J. Mater. Sci. 2010; 45:5291-5301.

3. Gardea-Torresdey JL, Tiemann KJ, Armendariz V, Bess-Oberto L, Chianelli RR, Rios J, Parsons JG, Gamez G. Characterization of $\mathrm{Cr}(\mathrm{VI})$ binding and reduction to $\mathrm{Cr}(\mathrm{III})$ by the agricultural 
byproducts of Avena monida (Oat) biomass. J Hazard Mater. 2000; 80(1-3):175-188. [PubMed: 11080577]

4. Luther S, Brogfeld N, Kim J, Parsons JG. Study of the thermodynamics of chromium(III) and chromium(VI) binding to iron(II/III)oxide or magnetite or ferrite and magnanese(II) iron(III) oxide or jacobsite or manganese ferrite nanoparticles. J. Colloid Interface Sci. 2013; 400:97-103. [PubMed: 23558081]

5. Sperling M, Shukun X, Bernhard W. Determination of Chromium(III) and Chromium(VI) in Water Using Flow Injection On-Line Preconcentration With Selective Adsorption on Activated Alumina and Flame atomic Absorption Spectrometric Detection. Anal. Chem. 1992; 64:3101-3108.

6. Sawalha MF, Gardea-Torresdey JL, Parsons JG, Geoffrey Saupe, Peralta-Videa JR. Determination of adsorption and speciation of chromium species by saltbush (Artiplex canescens) biomass using a combination of XAS and ICP-OES. Microchem J. 2005; 81(1):122-132.

7. Xiaofang T, Xianchao G, Feng Y, Yeqing L, J-D Mao, Lixiang Z. Catalytic role of soils in the transformation of $\mathrm{Cr}$ (VI) to $\mathrm{Cr}$ (III) in the presence of organic acids containing a-OH groups. Geoderma. 2010; 159(3):270-275.

8. Fendorf S, Zasoski R. Chromium(III) Oxidation by $\mathrm{MnO}_{2}$ 1. Characterization. Environ. Sci. Technol. 1992; 26:79-85.

9. Wu Y, Zhang J, Tong Y, Xu X. Chromium(VI) reduction in aqueous solutions by $\mathrm{Fe}_{3} \mathrm{O}_{4}$-stabilized $\mathrm{Fe}(0)$ nanoparticles. J. Hazard Mater. 2009; 172:1640-1645. [PubMed: 19740609]

10. Yavuz AG, Dincturk-Atalay E, Uygun A, Gode F, Aslan E. A comparison study of adsorption of $\mathrm{Cr}(\mathrm{VI})$ from aqueous solutions onto alkyl-substituted polyaniline/chitosan composites. Desalin. 2011; 279(1):325-331.

11. Wu Y, Deng B, Xu H, Kornishi H. Chromium(III) Oxidation Coupled with Microbially Mediated Mn(II) Oxidation. Geomicrobio J. 2005; 22:161-170.

12. Dai R, Liu J, Yu C, Sun R, Lan Y, J-D Mao. A Comparative study of oxidation of Cr (III) in aqueous ions, complex ions and insoluble compounds by manganese-bearing mineral (birnessite). Chemosphere. 2009; 76(4):536-541. [PubMed: 19342077]

13. Hu J, Chen G, Lo IMC. Selective removal of heavy metals from industrial wastewater using maghemite nanoparticle: performance and mechanisms. J. Environ. Eng. 2006; 132:709-715.

14. Schneider RM, Cavalin CF, Barros MASD, Tavares CRG. Adsorption of chromium ions in activated carbon. Chem. Eng. J. 2007; 132:355-000.

15. Hu J-S, Zhong L-S, Song W-G, Wan L-J. Synthesis of Hierarchically Structured Metal Oxides and their Application in Heavy Metal Ion Removal. Adv. Mater. 2008; 20:2977-2982.

16. Han RP, Zou WH, Zhang ZP, Shi J, Yang JJ. Removal of copper(II) and lead(II) from aqueous solution by manganese oxide coated sand. I. Characterization and kinetic study. J. Hazard. Mater. 2006; 137:384-395. [PubMed: 16603312]

17. Asiri AM, Khan SB, Alamry KA, Marwani HM, Rahman MM. Growth of $\mathrm{Mn}_{3} \mathrm{O}_{4}$ on cellulose matrix: Nanohybrid as a solid phase adsorbent for trivalent chromium. Appl Surf Sci. 2013; 270:539-544.

18. Li L, Fan L, Sun M, Qiu H, Li X, Duann H, Luo C. Adsorbent for chromium removal based on graphene oxide Functionalized with magnetic Cyclodextrin-chitosan. Colloids Surf B: Biointerfaces. 2013; 107:76-83. [PubMed: 23466545]

19. Parsons JG, Lopez ML, Peralta-Videa JR, Gardea-Torresdey JL. Determination of arsenic (III) and arsenic (V) binding to microwave assisted hydrothermal synthetically prepared $\mathrm{Fe}_{3} \mathrm{O}_{4}, \mathrm{Mn}_{3} \mathrm{O}_{4}$, and $\mathrm{MnFe}_{2} \mathrm{O}_{4}$ nanoadsorbents. Microchem J. 2008; 91(1):100-106.

20. Huang R, Yang B, Liu Q. Removal of Chromium(VI) Ions From Aqueous Solutions with Protonated Crosslinked Chitosan. J. Appl. Polymer Sci. 2013; 129:908-915.

21. Weilong W, Xiaobo F. "Efficient Removal of Cr(IV) with Fe/Mn Mixed Metal Oxide Nanocomposites Synthesized by a Grinding Method. J. Nanomater. 2013; 2013:1-8.

22. Yavuz O, Altunkaynak Y, Guzel F. Removal of copper, nickel, cobalt and manganese from aqueous solution by kaolinite. Water Res. 2003; 37:948-52. [PubMed: 12531278]

23. Wang YH, Lin SH, Juang RS. Removal of heavy metal ions from aqueous solutions using various low-cost adsorbents. J. Hazard. Mater. B. 2003; 102:291-302. 
24. Hu J, Wang SW, Shao DD, Dong YH, Li JX, Wang XK. Adsorption and Reduction of Chromium (VI) from Aqueous Solutions by Multiwalled Carbon Nanotubes. Enviorn Pollut Toxicol J. 2009; 1:66-73.

25. Dakiky M, Khamis M, Manassra A, Mereb M. Selective adsorption of chromium(VI) in industrial wastewater using low-cost abundantly available adsorbents. Adv. Environ. Res. 2002; 6(4):533540.

26. Gonzalez C, Hernandez J, Parsons JG, Gardea-Torresdey JL. A study of the removal of selenite and lelenate from aqueous solutionsusing a magnetic iron/manganese oxide nanomaterial and ICPMS. Microchem J. 2010; 96(2):324-329.

27. Mallick S, Dash SS, Parida KM. Adsorption of hexavalent chromium on manganese nodule leached residue obtained from $\mathrm{NH}_{3}-\mathrm{SO}_{2}$ leaching. J. Colloid and Interface Sci. 2006; 297(2):419425. [PubMed: 16330035]

28. Jarosch D. Crystal Structure Refinement and Reflectance Measurements of Hausmannite, $\mathrm{Mn}_{3} \mathrm{O}_{4}$. Mineral. Petrol. 1987; 37:15-23.

29. Landrot G, Ginder-Vogel M, Livi K, Fitts JP, Sparks DL. Chromium(III) oxidation by three poorly-crystalline manganese(IV) oxides. 1. Chromium(III)-oxidizing capacity. Environ Sci Technol. 2012; 46:11594-600. [PubMed: 23050871]

30. Gupta VK, Agarwal S, Saleh TA. Chromium removal combining the magnetic properties of iron oxide with adsorption properties of carbon nanotubes. Water Res. 2011; 45:2207-2212. [PubMed: 21303713]

31. Ajouyeda O, Hurel C, Ammari M, Allal LB, Marmier N. Sorption of Cr(VI) onto natural iron and aluminum (oxy)hydroxides: Effects of $\mathrm{pH}$, ionic strength and initial concentration. J Hazard Mater. 2009; 174:616-622. [PubMed: 19818554]

32. Yuan P, Fan M, Yang D, He H, Liu D, Yuan A, Zhu JX, Chen TH. Montmorillonite-supported Magnetite nanoparticles for the removal of hexavalent chromium [Cr(VI)] from aqueous solutions. J. Hazard Mater. 2009; 166:821-829. [PubMed: 19135796]

33. Wang P, Lo IMC. Synthesis of mesoporous magnetic $\gamma-\mathrm{Fe}_{2} \mathrm{O}_{3}$ and its application to $\mathrm{Cr}(\mathrm{VI})$ removal from contaminated water. Water Res. 2009; 43:3727-3734. [PubMed: 19559458]

34. Gasser MS, Morad GHA, Aly HF. Batch kinetics and thermodynamics of chromium ions removal from waste solutions using synthetic adsorbents. J. Hazard Mater. 2007; 142:118-129. [PubMed: 16982142]

35. Panday KK, Prasad G, Singh VN. Removal of Cr(VI) from aqueous solutions by adsorption on fly ash-wollastonite. J. Chem. Technol. Bioechnol. A. 34(1984):367-374.

36. Gupta VK, Park KT, Sharma S, Mohan D. Removal of chromium(VI) from electroplating industry wastewater using bagasse flyash—a sugar industry waste material. Environmentalist. 1999; 19:129-136.

37. Erdem M, Altundogan HS, Tumen F. Removal of hexavalent chromium by using heat-activated bauxite. Min. Eng. 2004; 17:1045-1052.

38. Tel H, Alta Y, Taner MS. Adsorption characteristics and separation of $\mathrm{Cr}(\mathrm{III})$ and $\mathrm{Cr}(\mathrm{VI})$ on hydrous titanium(IV) oxide. J. Hazard. Mater. 2004; 112(3):225-231. [PubMed: 15302443]

39. Gupta VK, Gupta M, Sharma S. Process development for the removal of lead and chromium from aqueous solutions using red mud----an aluminium industry waste. Water Res. 2001; 35:11251134. [PubMed: 11268832]

40. Santiago, I.; Worland, VP.; Cazares-Rivera, E.; Cadena, FC. Adsorption of HexavalentChromium onto Tailored Zeolites. In Proceedings of 47th Purdue Industrial Waste Conference,West Lafayette, IN, USA. Vol. Volume 1. Lewis Publishers, Inc; Chelsea, MI, USA: May 11-13. 1992 p. 669-710.

41. Leppert D. Heavy metal sorption with clinoptilolite zeolite: alternatives for treating contaminated soil and water. Mining Eng. 1990; 42:604-608.

42. Mor S, Ravindra K, Bishnoi NR. Adsorption of chromium from aqueous solution by activated alumina and activated charcoal. Bioresource Technol. 2007; 98:954-957.

43. Rodrigues LA, Maschio LJ, Evangelista da Silva R, Pintoda Silva MLC. Adsorption of Cr(VI) from aqueous solution by hydrous zirconium oxide. J. Hazard. Mater. 2010; 173:630-636. [PubMed: 19748728] 
44. Khan SA, Rehman RU, Khan MA. Adsorption of chromium (III), chromium (VI) and silver (I) on bentonite. Waste Manage. 1995; 15:271-282.

45. Alvarez-Ayuso E, Garcia-Sanchez A, Querol X. Adsorption of $\mathrm{Cr}(\mathrm{VI})$ from synthetic solutions and electroplating wastewaters on amorphous aluminium oxide. J. Hazard. Mater. 2007; 142:191-198. [PubMed: 16978771]

46. Krishna BS, Murty DSR, Prakash BSJ. Thermodynamics of Chromium(VI) Anionic Species Sorptiononto Surfactant-Modified Montmorillonite Clay. J Colloid Interface Sci. 2000; 229:230236. [PubMed: 10942564]

47. Musorrafiti MJ, Konek CT, Hayes PL, Geiger FM. Interaction of Chromium(VI) with the aAluminum Oxide-Water Interface. J. Phys. Chem. C. 2008; 112:2032-2039.

48. Azizian S. Kinetic models of sorption: a theoretical analysis. J. Colloid Interface Sci. 2004; 276:47-52. [PubMed: 15219428]

49. Yuan P, Liu D, Fan M, Yang D, Zhu R, Ge F, Zhu J, He H. Removal of hexavalent chromium $[\mathrm{Cr}(\mathrm{VI})]$ from aqueous solutions by thediatomite-supported/unsupported magnetite nanoparticles. J. Hazard. Mater. 2010; 173:614-621. [PubMed: 19748178]

50. Jiang W, Pelaez M, Dionysiou DD, Entezari MH, Tsoutsou D, O'Shea K. Chromium(VI) removal by maghemite nanoparticles. Chem. Eng. J. 2013; 222:527-533.

51. Bilgin Simsek E, Beker U. Kinetic Performance of Aluminum and Iron Oxides in the Removal of Arsenate from Aqueous Environment. J. Clean Energy Technol. 2014; 2:206-209.

52. Boparai HK, Joseph M, O'Carroll DM. Kinetics and thermodynamics of cadmium ion removal by adsorption onto nano-zerovalent iron particles. J. Hazard. Mater. 2011; 186:458-465. [PubMed: 21130566] 


\section{Highlights}

The binding of $\mathrm{Cr}(\mathrm{III})$ and $\mathrm{Cr}(\mathrm{VI})$ to $\mathrm{Mn}_{3} \mathrm{O}_{4}$ nanomaterials was investigated

Effects of $\mathrm{pH}$, temperature, and time were investigated for the binding

$\mathrm{Cr}$ (III) capacity at 277,294 , and $318 \mathrm{~K}$ was $18.7,41.7$, and $54.4 \mathrm{mg} / \mathrm{g}$

$\mathrm{Cr}(\mathrm{VI})$ capacity at 277,294 , and $318 \mathrm{~K}$ were $2.5,43$, and $5.8 \mathrm{mg} / \mathrm{g}$

Thermodynamic parameters $\Delta \mathrm{G}, \Delta \mathrm{H}, \Delta \mathrm{S}$, and $\mathrm{E}_{\mathrm{a}}$ were determined 

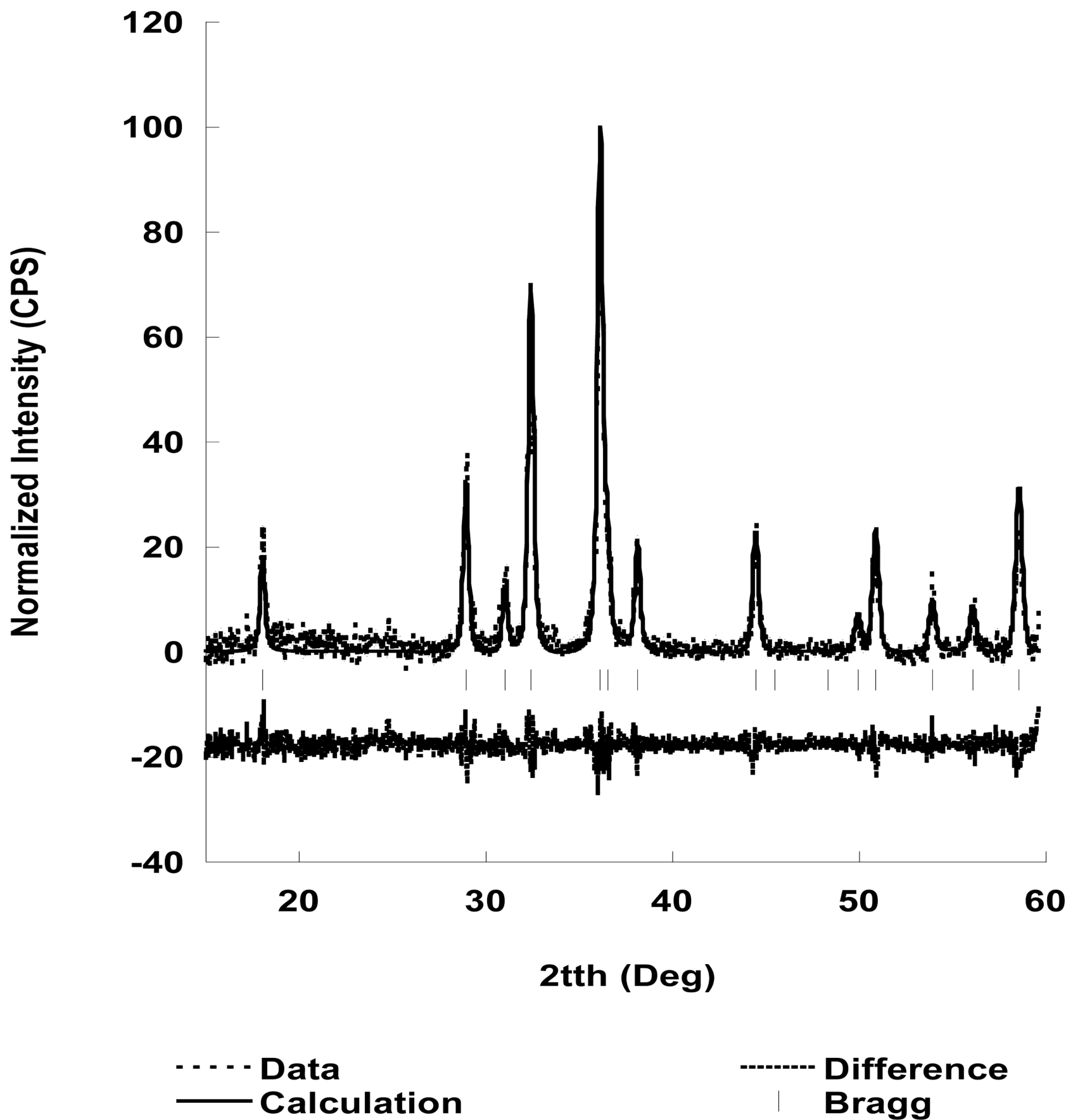

Figure 1.

X-Ray Diffraction pattern for the synthesized $\mathrm{Mn}_{3} \mathrm{O}_{4}$ nanomaterials, showing the fitting, the difference pattern between the fitting and the raw data, and the Bragg peaks. 

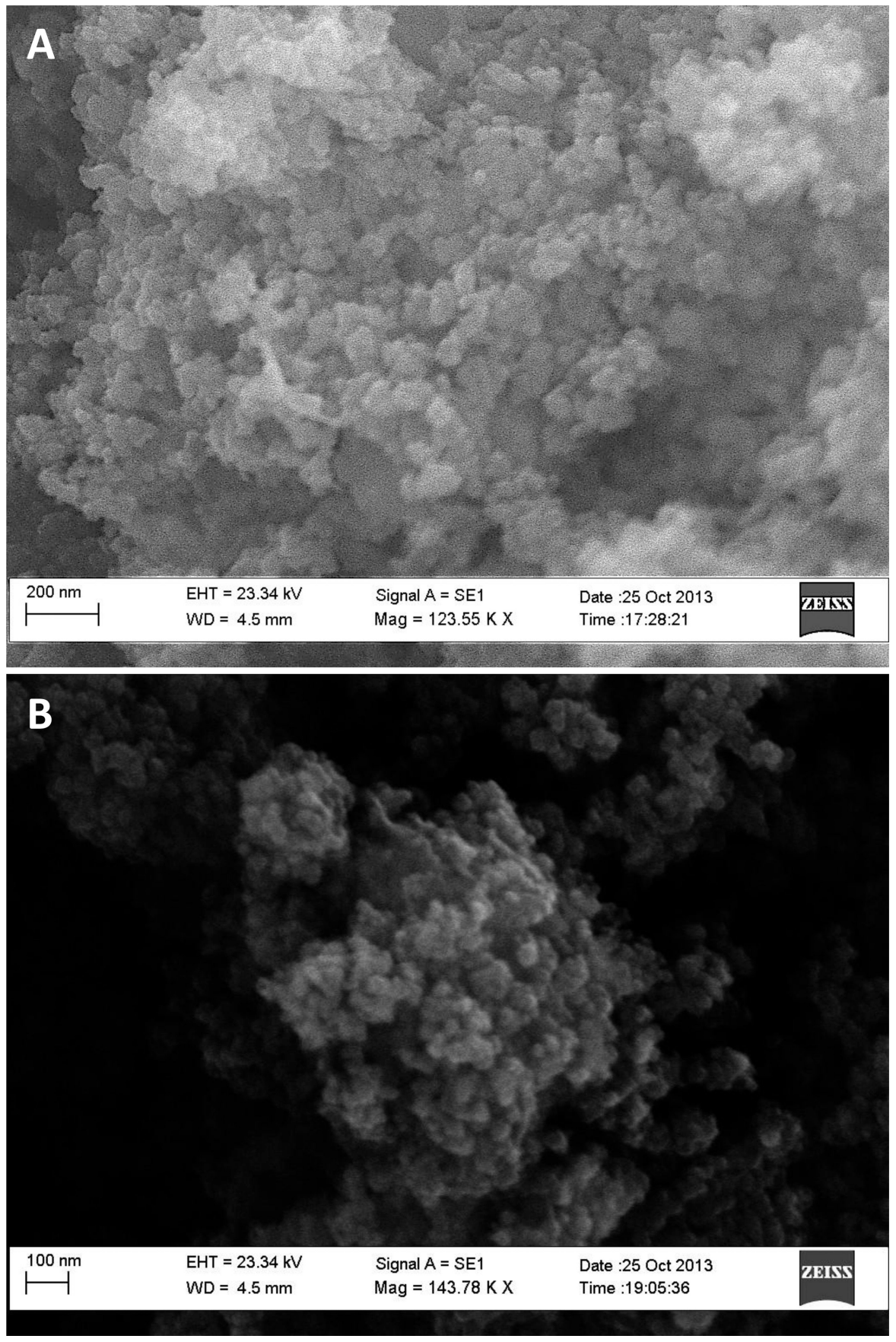

Figure 2.

A. SEM image taken at $123.55 \mathrm{~K} \mathrm{X}$ of the synthesized $\mathrm{Mn}_{3} \mathrm{O}_{4}$ nanomaterials $\mathbf{B}$. SEM image taken at $143.8 \mathrm{~K} \mathrm{X}$ of the synthesized $\mathrm{Mn}_{3} \mathrm{O}_{4}$ nanomaterials. SEM images were taken after washing and drying at $60^{\circ} \mathrm{C}$ for 24 hours. 
A
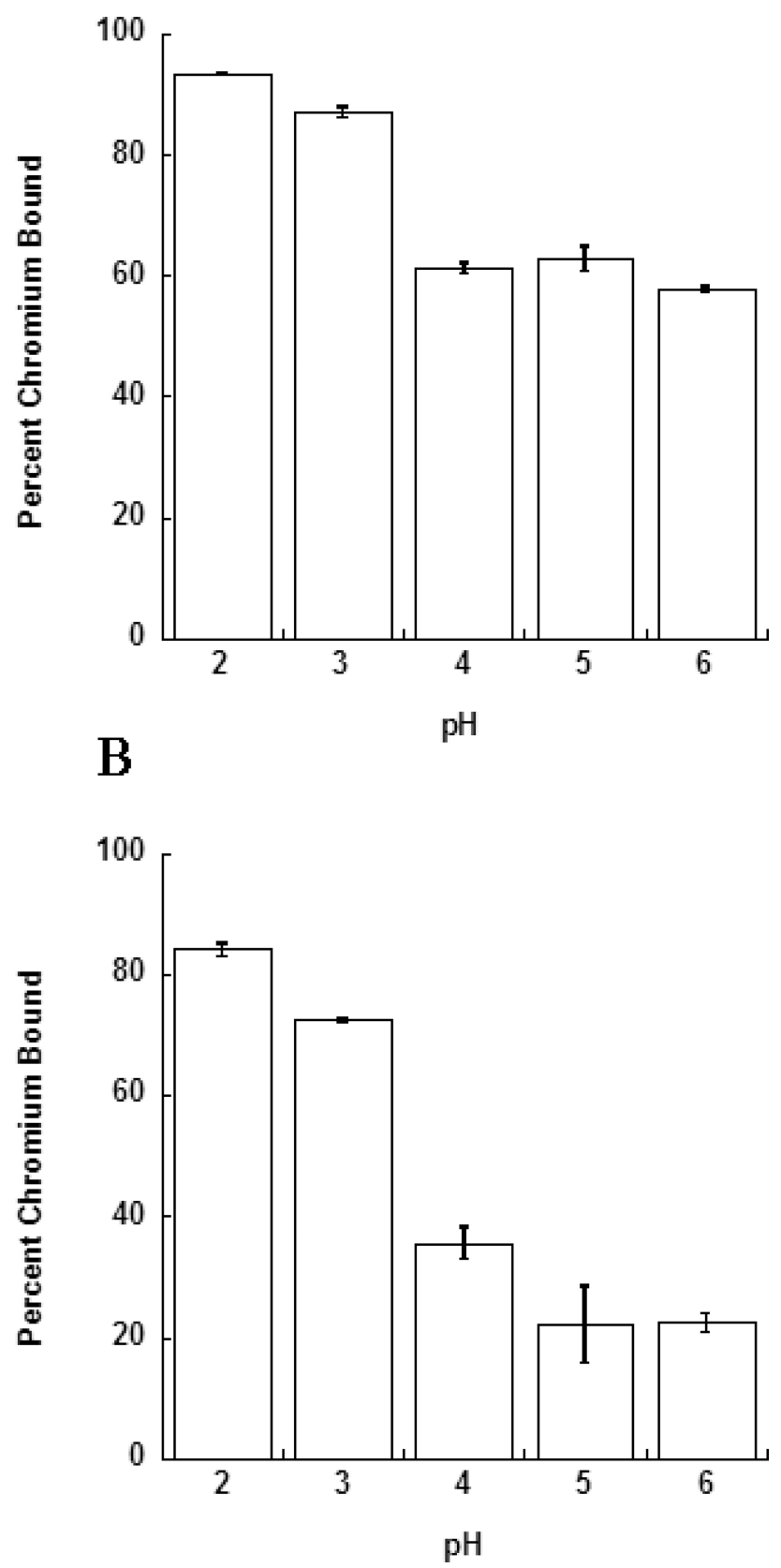

Figure 3.

A. Effect of $\mathrm{pH}$ on the binding of a $300 \mathrm{ppb}$ solution chromium (III) from chromium (III) nitrate to $\mathrm{Mn}_{3} \mathrm{O}_{4}$ at $25^{\circ} \mathrm{C}$. B. Effect of $\mathrm{pH}$ on the binding of a $300 \mathrm{ppb}$ solution chromium (VI) from potassium dichromate to $\mathrm{Mn}_{3} \mathrm{O}_{4}$ at $25^{\circ} \mathrm{C}$. 


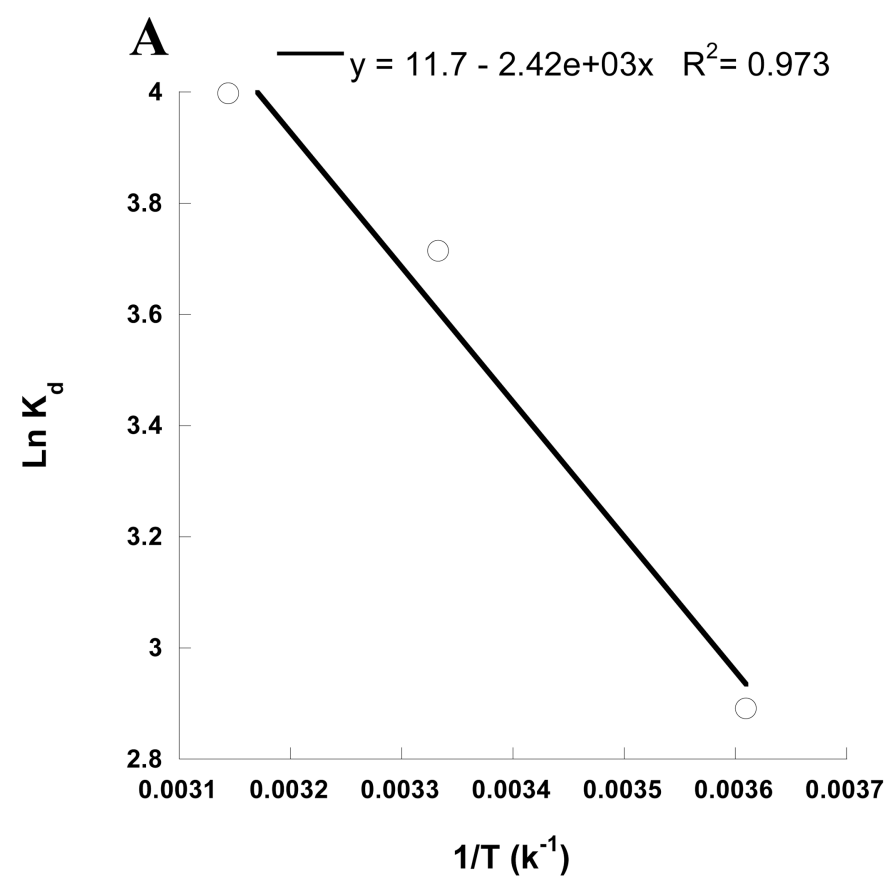

\section{B}

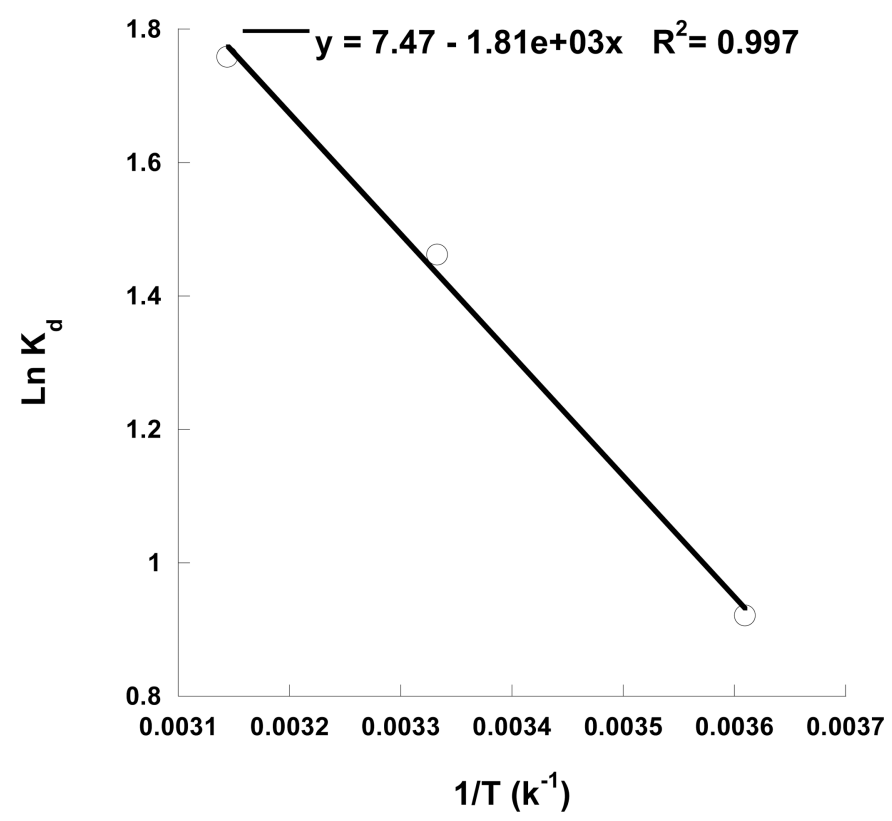

Figure 4.

A. Thermodynamic plot for the sorption of chromium(III) to the $\mathrm{Mn}_{3} \mathrm{O}_{4}$ nanomaterial after 1 hour of contact time. B. Thermodynamic plot for the sorption of chromium(VI) to the $\mathrm{Mn}_{3} \mathrm{O}_{4}$ nanomaterial after 1 hour of contact time. 


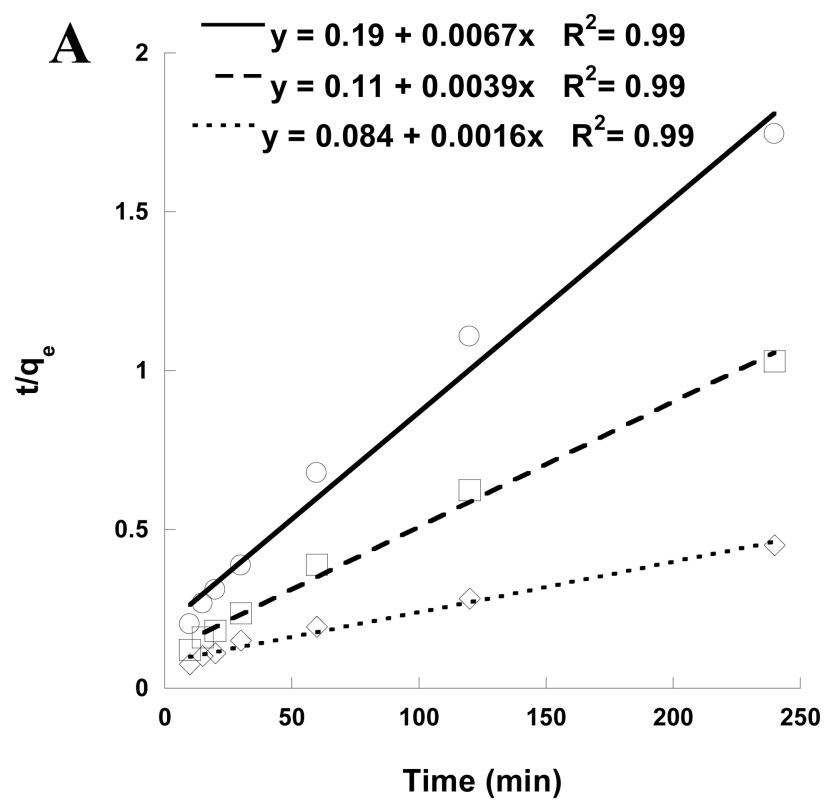

$\neg \mathrm{Cr}(\mathrm{III}) 4 \mathrm{C} \quad--\mathrm{Cr}(\mathrm{III}) 25 \mathrm{C} \quad \cdots \cdots \cdot \mathrm{Cr}(\mathrm{III}) 45 \mathrm{C}$

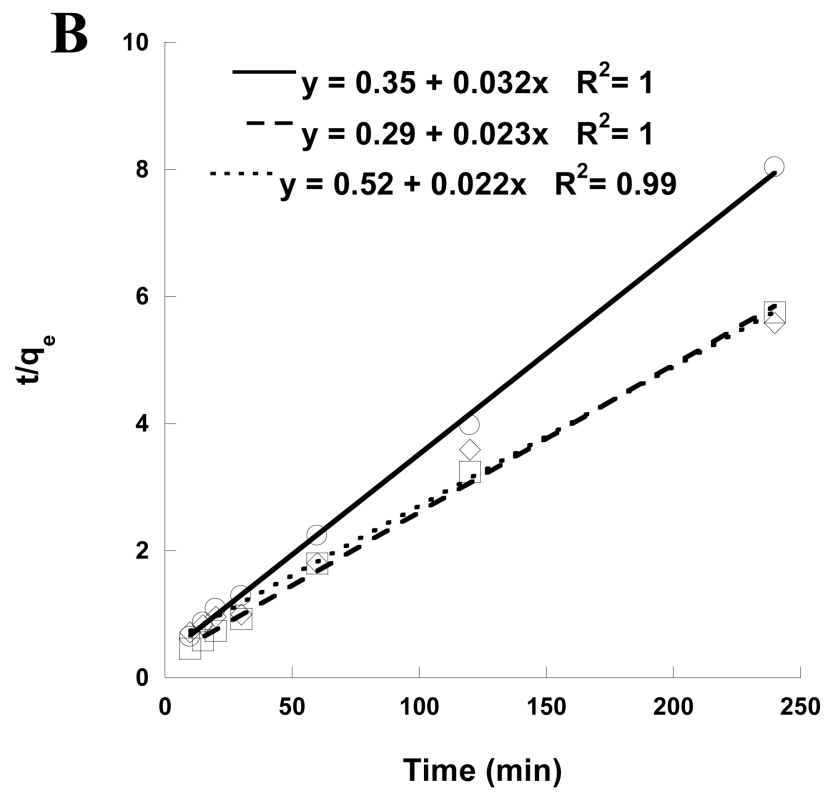

$\smile \mathrm{Cr}(\mathrm{VI}) 4 \mathrm{C} \quad--\mathrm{Cr}(\mathrm{VI}) 25 \mathrm{C} \quad \cdots \cdots \mathrm{Cr}(\mathrm{VI}) 45 \mathrm{C}$

Figure 5.

A. Kinetics plots for chromium(III) chromium(VI) (B) at temperature of $4{ }^{\circ} \mathrm{C}, 25^{\circ} \mathrm{C}$, and $45^{\circ} \mathrm{C}$ for the reaction of $3 \mathrm{mM}$ chromium ion with $10 \mathrm{mg}$ of the $\mathrm{Mn}_{3} \mathrm{O}_{4}$ nanomaterial. B. Kinetics plots for chromium(VI) at temperature of $4{ }^{\circ} \mathrm{C}, 25^{\circ} \mathrm{C}$, and $45^{\circ} \mathrm{C}$ for the reaction of 3 $\mathrm{mM}$ chromium ion with $10 \mathrm{mg}$ of the $\mathrm{Mn}_{3} \mathrm{O}_{4}$ nanomaterial. 


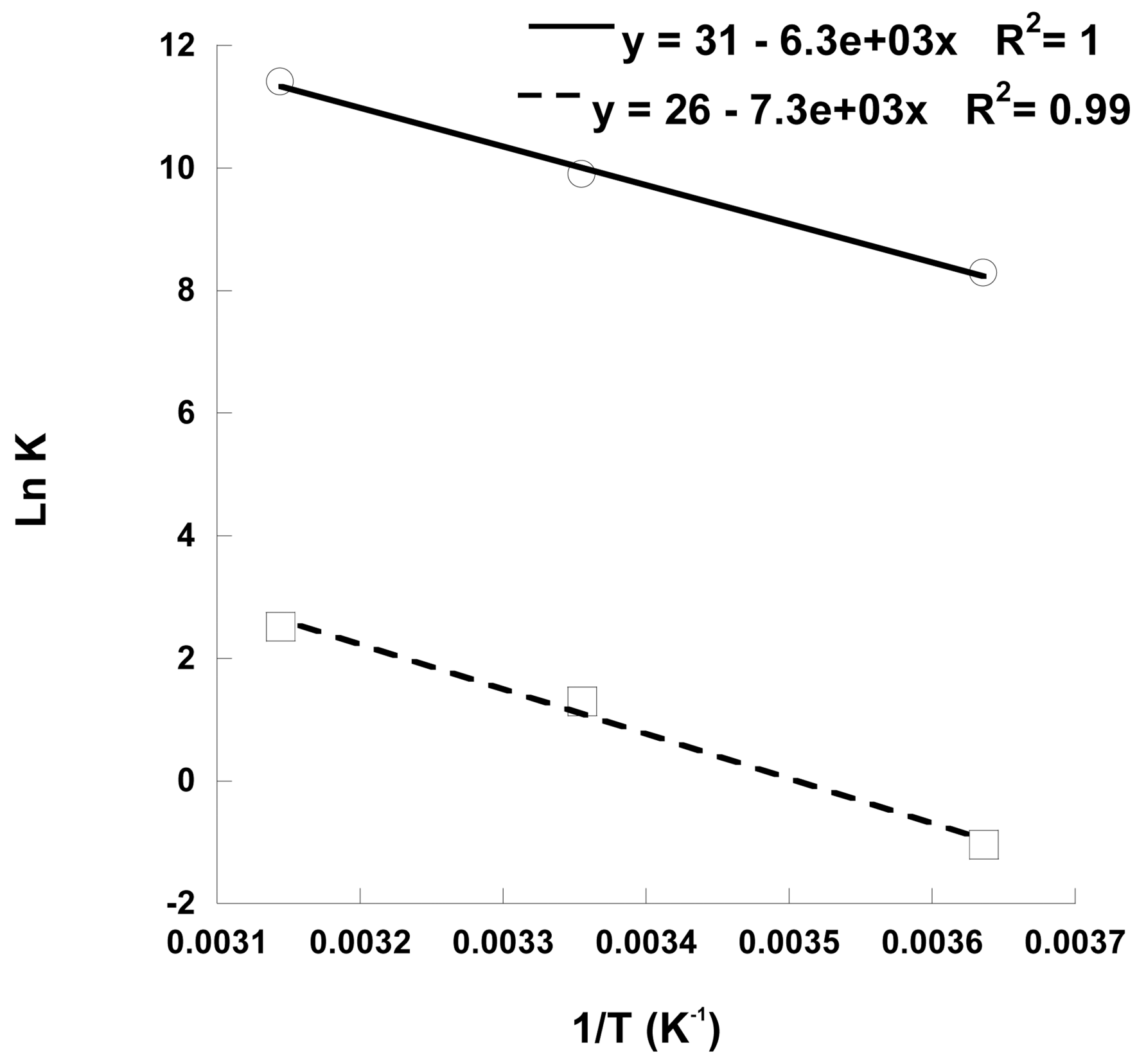

\section{- Ln K Chromium (III)

Figure 6.

Arrhenius plot for the chromium(III) and Chromium(VI) binding to the $\mathrm{Mn}_{3} \mathrm{O}_{4}$ nanomaterial, data obtained from the kinetics for the chromium(III) and chromium(VI) kinetics at different temperatures. 


\section{Table 1}

ICP-OES operational parameters used for the analysis of chromium concentrations in solution after reaction with the different nanoadsorbents.

\begin{tabular}{l|l}
\hline Parameter & Setting \\
\hline$\lambda$ & $267.716 \mathrm{~nm}$ \\
RF power & $1500 \mathrm{~W}$ \\
Nebulizer & Gemcone (low flow) \\
Plasma Flow & $15 \mathrm{~L} / \mathrm{min}$ \\
Auxiliary Flow & $0.2 \mathrm{~L} / \mathrm{min}$ \\
Nebulizer Flow & $0.55 \mathrm{~L} / \mathrm{min}$ \\
Sample Flow & $1.50 \mathrm{~mL} / \mathrm{min}$ \\
Injector & $2.0 \mathrm{~mm}$ Alumina \\
Spray Chamber & Cyclonic \\
Integration Time & $10-20$ seconds \\
\hline
\end{tabular}




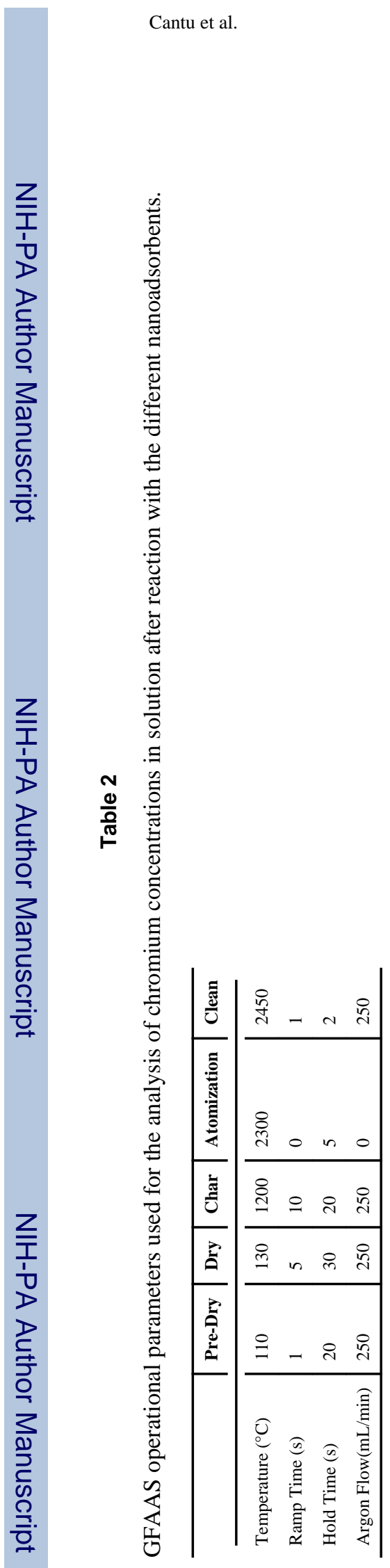

Chem Eng J. Author manuscript; available in PMC 2015 October 15. 


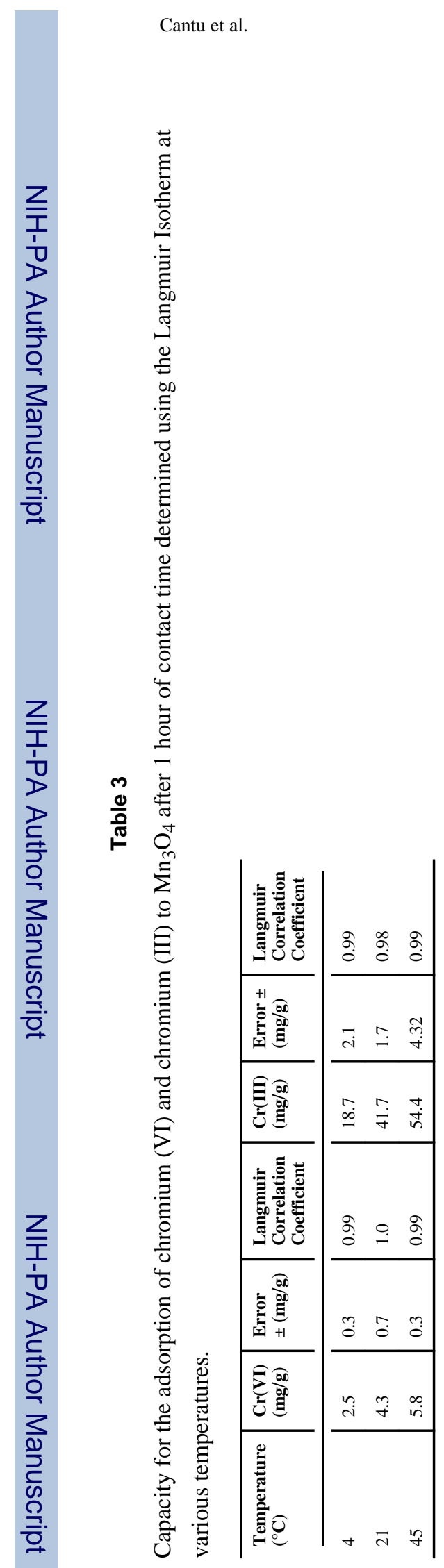

Chem Eng J. Author manuscript; available in PMC 2015 October 15. 
Table 4

Capacities for chromium to different metal oxide materials from the literature.

\begin{tabular}{l|l|l|l}
\hline Material & $\begin{array}{l}\text { Chromium } \\
\text { Capacity (mg/g) }\end{array}$ & Chromium Species & Reference \\
\hline $\mathrm{AlOOH}$ & 2.158 & Chromium(VI) & 31 \\
$\mathrm{Fe}_{3} \mathrm{O}_{4}$ (nanoparticles) & 21.7 & Chromium(VI) & 32 \\
$\mathrm{Fe}_{3} \mathrm{O}_{4}$ (nanoparticles)-diatomite & 69.2 & Chromium(VI) & 32 \\
$\mathrm{Fe}_{3} \mathrm{O}_{4}$ (micro particles) & 10.6 & Chromium(VI) & 32 \\
$\mathrm{Fe}_{3} \mathrm{O}_{4}$ ((micro particles)-diatomite & 11.4 & Chromium(VI) & 32 \\
$\gamma-\mathrm{Fe}_{2} \mathrm{O}_{3}$ (nanoparticles) & 15.6 & Chromium(VI) & 33 \\
$\mathrm{TiO}_{2}$ & 14.56 & Chromium(VI) & 34 \\
$\mathrm{Wollastonite-Fly} \mathrm{ash}_{\mathrm{Bagasse} \mathrm{fly} \mathrm{ash}}$ & 0.271 & Chromium(VI) & 35 \\
Bauxite & 259.0 & Chromium(III) & 36 \\
Bauxite & 0.5 & Chromium(VI) & 37 \\
Hydrous titanium(IV) oxide & 0.4 & Chromium(VI) & 37 \\
Red Mud & 5.0 & Chromium(VI) & 38 \\
Zeolite & 21.1 & Chromium(VI) & 39 \\
Zeolite & 19.67 & Chromium(III) & 40 \\
\hline
\end{tabular}


Table 5

Calculated change in Gibbs free energy for the binding of $\mathrm{Cr}$ (III) and $\mathrm{Cr}$ (VI) to the $\mathrm{Mn}_{3} \mathrm{O}_{4}$ nanomaterial at various temperatures.

\begin{tabular}{ccc}
\hline $\begin{array}{c}\text { Chromium Species } \\
\text { (Temp. K) }\end{array}$ & $\mathbf{\Delta G}(\mathbf{k J} / \mathbf{m o l})$ & $\begin{array}{c}\text { Error } \boldsymbol{\Delta G} \\
(\mathbf{\pm k J} / \mathbf{m o l})\end{array}$ \\
\hline Cr (III) (277) & -2.9 & 0.1 \\
Cr (III) (298) & -10.7 & 0.9 \\
Cr (III) (318) & -13.7 & 1.2 \\
Cr (VI) (277) & -0.9 & 0.1 \\
Cr (VI) (298) & -2.8 & 0.02 \\
Cr (VI) (318) & -3.9 & 0.14 \\
\hline
\end{tabular}




\section{Table 6}

Thermodynamic paramerters $\Delta \mathrm{H}$ and $\Delta \mathrm{S}$ calculated for the binding of chromium(III) and chromium(VI) binding to $\mathrm{Mn}_{3} \mathrm{O}_{4}$ nanomaterials.

\begin{tabular}{lcc}
\hline Chromium Species & AH $(\mathbf{k J} / \mathbf{m o l})$ & AS $(\mathbf{J} / \mathbf{m o l})$ \\
\hline $\mathrm{Cr}(\mathrm{III})$ & 70.6 & 267.7 \\
$\mathrm{Cr}(\mathrm{VI})$ & 19.1 & 72.8 \\
\hline
\end{tabular}


Table 7

Rate constants determined for the reaction of chromium(III) and Chromium(VI) binding to $\mathrm{Mn}_{3} \mathrm{O}_{4}$ nanomaterials at temperatures of $4{ }^{\circ} \mathrm{C}, 25^{\circ} \mathrm{C}$, and $45^{\circ} \mathrm{C}$.

\begin{tabular}{l|l|l}
\hline Reaction & $\mathbf{k}\left(\mathbf{g ~ m g}^{-1} \mathbf{m i n}^{-1}\right)$ & $\mathbf{R}^{\mathbf{2}}$ \\
\hline Chromium(III) $4{ }^{\circ} \mathrm{C}$ & 3929 & 0.99 \\
Chromium(III) $25^{\circ} \mathrm{C}$ & 19834 & 0.99 \\
Chromium(III) $45^{\circ} \mathrm{C}$ & 89000 & 0.99 \\
Chromium(VI) $4{ }^{\circ} \mathrm{C}$ & 0.36 & 1 \\
Chromium(VI) 25 $5^{\circ} \mathrm{C}$ & 3.65 & 1 \\
Chromium(VI) 45 ${ }^{\circ} \mathrm{C}$ & 12.35 & 0.99
\end{tabular}




\section{Table 7}

Determined activation energies for the binding of chromium(III) and chromium(VI) to the $\mathrm{Mn}_{3} \mathrm{O}_{4}$ nanomaterials.

\begin{tabular}{l|l|l}
\hline \hline Reaction & $\mathbf{E}_{\mathbf{a}}(\mathbf{K J})$ & $\mathbf{R}^{\mathbf{2}}$ \\
\hline Chromium(III) & 52.5 & 1 \\
Chromium(VI) & 60.7 & 0.99 \\
\hline
\end{tabular}

